\title{
Engagement with different nightlife venues and frequent ecstasy use in a young adult
}

\section{population}

Abbreviated title: Nightlife venues and frequent ecstasy use

Ellen M Leslie ${ }^{1,2}$, Andrew Smirnov ${ }^{2}$, Adrian Cherney ${ }^{1}$, Helene Wells ${ }^{3,4}$, Robert Kemp ${ }^{5}$, Margot Legosz ${ }^{3,6}$, Jake M Najman ${ }^{1,2}$

${ }^{1}$ School of Social Science, The University of Queensland, St Lucia, Queensland, Australia, 4072

${ }^{2}$ Queensland Alcohol and Drug Research and Education Centre, School of Population Health, The University of Queensland, Herston Rd, Herston, Queensland, Australia, 4006

${ }^{3}$ Crime and Misconduct Commission, North Tower Green Square, St Pauls Terrace, Fortitude Valley, Queensland, Australia, 4006

${ }^{4}$ Griffith Youth Forensic Service, Griffith University, Mt Gravatt, Queensland, Australia, 4122

${ }^{5}$ Drug Harm Reduction Branch, Queensland Health, Butterfield St, Herston, Queensland, Australian, 4006

${ }^{6}$ Arts, Education, and Law, Griffith University, Mt Gravatt, Queensland, Australia, 4122

Corresponding author:

Ellen M Leslie, Queensland Alcohol and Drug Research and Education Centre, Public Health Building, University of Queensland, Herston Rd, Herston, Queensland, 4006, Australia. Phone: +61733464618 Fax: +61733655509

Email: ellen.leslie@uqconnect.edu.au,e.leslie1@uq.edu.au 


\title{
Engagement with different nightlife venues and frequent ecstasy use in a young adult population
}

\begin{abstract}
Aims: Little is known about the possible influence of different social settings on changes in patterns of ecstasy use over time. This study explores the relationship between engagement with different types of nightlife venues and subsequent frequent ecstasy use in an Australian young adult population sample. Methods: Longitudinal data are from a population-derived sample of Australian young adult ecstasy users $(n=265)$. Attendance at four types of venues (nightclubs, electronic dance music events/music festivals, venues playing live music, and pubs/bars) was measured at 6 months. Frequency of recent ecstasy use (last 12 months) was measured at 12 and 30 months. A prediction model of frequent ecstasy use at 30 months was developed using Poisson regression reporting adjusted relative risk. Findings: Regular attendance at nightclubs ( $\geq$ monthly, Adjusted Relative Risk 6.21, CI 2.30-16.76) was associated with frequent ecstasy use at 30 months, independently of ecstasy use expectancies, ecstasy availability, ecstasy and methamphetamine dependence, frequent use of methamphetamine and alcohol, and other dimensions of ecstasy involvement (i.e., length of ecstasy use career and lifetime ecstasy consumption). Conclusions: Compared with attendees of other venues, nightclub attendees may be a special priority group for ecstasy harm and demand reduction interventions.
\end{abstract}

\section{Keywords}

Ecstasy (MDMA), nightlife, licensed venues, nightclubs, young adults, population patterns 


\section{Engagement with different nightlife venues and frequent ecstasy use in a young adult population}

Introduction

Ecstasy (MDMA; 3,4-methylenedioxymethamphetamine) has been linked to the rave scene since the mid-1980s (Green, Mechan, Elliott, O’Shea, \& Colado, 2003). However, contemporary social settings of ecstasy use have diversified, encompassing nightclubs, pubs, and music festivals (Boeri, Sterk, \& Elifson, 2004; Lee, Battle, Soller, \& Brandes, 2011). The quantity of ecstasy consumed can vary between different settings (ter Bogt \& Engels, 2005). Yet, little is known about the possible relationship with and influence of social settings on temporal changes in ecstasy use, and whether changes may vary according to regular involvement in different settings.

Ecstasy use: A social activity

Primarily a social activity, ecstasy use is embedded in social settings and enmeshed within the wider context of music, dancing, and connecting with others (Engels \& ter Bogt, 2004; Hunt \& Evans, 2008). Qualitative research has highlighted that ecstasy's subjective effects, including heightened communication and feelings of closeness with others (Baylen \& Rosenberg, 2006), motivate young adults' social use of ecstasy (Hunt \& Evans, 2008; Singer \& Schensul, 2011). Ecstasy use expectancies, stemming from users' subjective experiences, have been linked with varied usage patterns (Boys \& Marsden, 2003; Engels \& ter Bogt, 2004; Smirnov et al., 2013). However, the respective associations between venues, expectancies, and levels of ecstasy use have not been disentangled. 
Access to ecstasy and peer contacts

Any association between venue attendance and increased ecstasy use is potentially explicable by attendees' increased access to ecstasy through availability within venues or increased social contact with ecstasy-using peers. Market factors, such as ecstasy availability, may influence purchase and consumption decisions (Abdallah, Scheier, Inciardi, Copeland, \& Cottler, 2007; Goudie, Sumnall, Field, Clayton, \& Coles, 2007). However, due to the crosssectional nature of available research, it is unclear whether such factors lead to temporal changes in ecstasy use. Contact with ecstasy-using peers may influence ecstasy use patterns due to peers supplying ecstasy or encouraging use through their own consumption behaviour (Jacinto, Duterte, Sales, \& Murphy, 2008; Vervaeke, van Deursen, \& Korf, 2008).

Alcohol and methamphetamine use

Use of alcohol and methamphetamine are both linked with young adults' social recreational settings and leisure time activities (Hunt, Moloney, \& Fazio, 2014; Kelly, LeClair, \& Parsons, 2013). Similarly to ecstasy use expectancies, young peoples' alcohol and methamphetamine use expectancies are socially contextualised (LaBrie, Grant, \& Hummer, 2011; Lende, Leonard, Sterk, \& Elifson, 2007). This suggests that increases in ecstasy use could be linked with increases in either methamphetamine or alcohol use.

In this study we assess engagement with different venue types (nightclubs, electronic dance music events [EDMEs]/music festivals, venues playing live music, and pubs/bar) as predictors of frequent ecstasy use at 30 months in a population sample of Australian young adult ecstasy users. We adjust for other factors that may influence ecstasy use levels, including ecstasy use expectancies, ecstasy access, ecstasy and methamphetamine dependence, frequent use of methamphetamine and alcohol, and other dimensions of ecstasy involvement, including length of ecstasy use career and lifetime ecstasy consumption. 


\section{Method}

\section{Participants}

The Natural History Study of Drug Use (NHSDU) is a longitudinal study of drug use in a population sample of young adult amphetamine-type stimulant (ATS; i.e. ecstasy and methamphetamine) users in South-East Queensland, Australia. Population screening was used to recruit a probabilistic sample of ATS users and non-users. This method is described in detail elsewhere (Smirnov, Kemp, Wells, Legosz, \& Najman, 2014).

Data are from the NHSDU baseline interview and 6, 12, and 30-month follow-up waves. Eighty-seven cases $(24.7 \%)$ were excluded due to missing data, including 51 who did not complete follow-up data collection (final sample: $n=265$ ). Excluded participants were younger than the current sample $(\mathrm{t}=2.11, \mathrm{p}<0.05)$, but did not differ by $\operatorname{sex}\left(\chi^{2}=2.78, n s\right)$, employment status $\left(\chi^{2}=0.44, n s\right)$, or lifetime ecstasy consumption (average 195.1 pills vs. 174.5 pills among current sample; $\mathrm{z}=-1.06, n s)$.

\section{Measures}

Frequent ecstasy use at 30 months (outcome)

At 12 and 30 months, participants reported their frequency of ecstasy use in the last 12 months (categories: no use, less than monthly use, monthly use, and weekly use). A dichotomous variable was created to indicate frequent (vs. infrequent) ecstasy use. The frequent-use group comprised those who increased from lower-level to at least monthly ecstasy use between the 12- and 30-month follow-up ( $n=16)$, and also those who maintained at least monthly use across these time intervals $(n=11)$. The infrequent-use group comprised those whose ecstasy use decreased to 'less than monthly' or 'not at all' in the last 12 months ( $n=96)$, as well as those who maintained these low levels $(n=142)$. Monthly use was chosen as a threshold for frequent use on the basis of previous research, which indicates that ecstasy 
users tend to use once a week or less often even at the peak of their ecstasy use (Bruno et al., 2009; Smirnov, et al., 2013).

Engagement with nightlife venues

At 6 months, participants reported frequency of attendance at four venue types in the last 12 months (nightclubs, EDMEs/music festivals, venues playing live music, and pubs/bars).

Dichotomous variables were created for each venue type $(\geq$ monthly vs. $<$ monthly attendance).

Ecstasy use expectancies

At baseline, participants reported how often they experienced 'positive' psychological effects during ecstasy use (euphoria, increased confidence, increased libido, being talkative, being very friendly, and increased empathy/understanding). 'Strong positive subjective effects' was categorised as reporting $\geq 5$ of 6 effects 'every time/nearly every time' (upper quartile).

Ecstasy availability

We asked how often participants were unable to acquire ecstasy when wanted in the last 6 months at baseline and the last 12 months at 30 months. 'Ready access to ecstasy' was categorised as 'never/rarely' being unable to acquire ecstasy.

Ecstasy-using peers

At baseline and 12 months, participants reported how many ecstasy users they knew (by name or face). We created dichotomous variables for number of ecstasy-using peers at baseline and 12 months ( $\geq 40$ ecstasy-using peers [baseline median] vs. $<40$ ). 
Ecstasy involvement at baseline

Participants estimated the number of ecstasy pills they had ever taken. A median of 70 pills was used as a threshold for high lifetime consumption. To differentiate between intensity and duration of ecstasy involvement, a variable measuring length of ecstasy use career was included (years since first ecstasy use: 0-3, 4-5, 6-9).

Ecstasy and methamphetamine dependence

Lifetime ecstasy and methamphetamine dependence were evaluated at 12 months using the Illegal Drug Use Section of the World Health Organisation's Composite International Diagnostic Interview (WMH-CIDI), which applies diagnostic criteria for drug dependence from the Diagnostic and Statistical Manual of Mental Disorders (DSM-IV), and has reasonable individual-level concordance with the Structural Clinical Interview for DSM-IV (SCID; positive predictive value of 82.0 for DSM-IV lifetime diagnosis of drug dependence with abuse; Haro et al., 2006).

Alcohol and methamphetamine use Frequency of alcohol (last month) and methamphetamine use (last 12 months) was measured at the 12- and 30-month follow-ups. A dichotomous variable was constructed for increased frequency alcohol use at 30-months (increase in days of use in the last month vs. no increase). A dichotomous variable was also created to indicate frequent (vs. infrequent) methamphetamine use, constructed using the same threshold described above for the frequent ecstasy use variable. 
Analysis

This study comprises longitudinal analysis of NHDSU data. Due to the small numbers in some outcome categories, we used Poisson regression to develop a prediction model of frequent ecstasy consumption at 30 months (Zou, 2004). We report unadjusted relative risks (RRs) and RRs adjusted for all variables in the model. Because Poisson regression can overestimate standard errors when applied to binomial data, a robust error variance method (sandwich estimation) was adopted (Zou, 2004). Wald tests were conducted to develop the most parsimonious model. Additional variables (i.e., ecstasy access at baseline, number of ecstasy-using peers at 12 months, lifetime ecstasy consumption, lifetime methamphetamine dependence at 12 months, frequency of alcohol use, frequent methamphetamine use, age and income) were examined but did not make a significant difference $\left(\chi^{2}=2.89, n s\right)$ and were excluded from the final model. Data were analysed using Stata/SE 12.1.

Results

Baseline sample characteristics

Table 1 compares ecstasy users' and non-users' baseline characteristics. Ecstasy users did not differ significantly from non-users in level of education, employment status, or educational attendance. However, a significantly higher proportion of ecstasy users earned more than $\$ 975$ per fortnight compared to non-users.

\section{TABLE 1 ABOUT HERE}

Frequent ecstasy use at 30 months

The proportions of ecstasy users with increased or stable monthly use, decreased use, stable low frequency ecstasy use at the 30-month follow-up, and no use at the 12- and 30-month 
follow-ups are presented in Table 2, with the mean number of days of use for each group. Just over $10 \%$ reported increased or stable high frequency (i.e. monthly) use and the mean number of days of use was highest in this group.

\section{TABLE 2 ABOUT HERE}

Predictors of frequent ecstasy use

Table 3 presents unadjusted and adjusted RRs for predictors of frequent ecstasy use at 30 months. In unadjusted and adjusted analyses, monthly (or more frequent) attendance at nightclubs, but not other venue types, significantly predicted frequent use at 30 months. Strong positive subjective effects and ready access to ecstasy at 30 months were also significant predictors. There were marginal non-significant results for venues playing live music (Adjusted RR 2.18, CI 0.95-4.98), number of ecstasy using peers at baseline (Adjusted RR 1.93, CI 0.93-3.99), and lifetime ecstasy dependence (Adjusted RR 1.94, CI 0.93-4.05). It is possible that a study with greater statistical power may find these factors to be related to subsequent frequency of ecstasy use. Length of ecstasy use career and sex were not significant predictors.

\section{TABLE 3 ABOUT HERE}

\section{Discussion}

Monthly or more frequent nightclub attendance early in our study increased the likelihood (over six-fold) of frequent ecstasy use at 30 months in a population sample of Australian young adult ecstasy users. In contrast, regular attendance at other nightlife venues did not predict frequent use. The association between regular nightclub attendance and frequent 
ecstasy use was not attenuated by ecstasy use expectancies, ecstasy availability, ecstasy or methamphetamine dependence, frequent use of methamphetamine or alcohol, or other dimensions of ecstasy involvement.

These findings suggest there may be something specific to the nightclub setting that leads to increased or sustained levels of regular ecstasy use. There are a number of possible mechanisms by which this may occur. The nightclub environment may be distinct from other licensed venues (e.g. pubs/bars) in the extent to which ecstasy use is accepted (Duff, 2005; Miller, Furr-Holden, Voas, \& Bright, 2005; Sanders, 2005), but this does not necessarily explain different findings for other settings, especially EDMEs. In contrast to these settings, nightclubs are open regularly, often with long hours and in close proximity to one another and, consequently, may provide greater access to drug-related social activities (Sanders, 2005). Nightclubs may also differ from EDMEs in cultural aspects, perhaps not engaging in the same way with 'ritualistic' elements of ecstasy use (Kavanaugh \& Anderson, 2008). Further, aspects of nightclub design and management have been shown to increase binge alcohol consumption (Kypri, Paschall, Maclennan, \& Langley, 2007) and it is possible there is a commensurate effect with regard to ecstasy use (Miller, Holder, \& Voas, 2009; Van Havere, Vanderplasschen, Lammertyn, Broekaert, \& Bellis, 2011).

While our findings do not support the proposition that frequent ecstasy use is related to ecstasy dependence, this possibility cannot be entirely excluded. However, previous research suggests that regular involvement in ecstasy use may be relatively transient (von Sydow, Lieb, Pfister, Höffler, \& Wittchen, 2002). More generally, it appears that many features of typical dependence syndromes, including physical aspects of dependence and associated long-term harms, are not applicable to ecstasy use (Degenhardt, Bruno, \& Topp, 2010). Instead, the most harmful consequences of ecstasy use appear to be attributable to 'binge' patterns of use, which increase exposure to acute and short-term risks (Baggott, 2002; 
Degenhardt et al., 2009). Thus, factors that extend or maintain periods of frequent ecstasy use may increase the levels of risk involved.

Implications

The unique association between regular nightclub attendance and frequent ecstasy use suggests nightclub patrons are a significant target group for demand and harm reduction strategies. Potential strategies may include location-based educational and behavioural interventions that target drug use in-situ and, therefore, have the potential to directly impact on behaviour to reduce drug-related harm (Akbar et al., 2011; Falck, Carlson, Wang, \& Siegal, 2004).

\section{Limitations}

We did not collect venue attendance data at 30 months, and therefore cannot fully explain the association between nightclub attendance and frequent ecstasy use. Such an association may reflect ongoing patterns of venue attendance or other behavioural changes. Our findings could also be explained by individual factors we did not measure, which may be associated with nightclub attendance and ecstasy use (e.g., sensation-seeking). Additionally, our ecstasy use measure relied on participant self-report. Because not all substances sold as ecstasy in Australia comprise MDMA, our findings are not necessarily specific to MDMA use. Lastly, our study did not measure aspects of drug use episodes specific to different nightlife settings (e.g., drug acquisition, dosage, timing of consumption). Further research, adopting a momentary ecological approach measuring such aspects, would be useful for elucidating the drug use patterns occurring within different settings. 


\section{Conclusion}

This study indicates that regular attendance at nightclubs, but not other venues, predicts subsequent frequent ecstasy use, independently of ecstasy use expectancies, access to ecstasy, ecstasy and methamphetamine dependence, frequent methamphetamine and alcohol use, and other dimensions of ecstasy involvement. There may be some justification for location-based interventions targeting nightclubs as opposed to other nightlife settings.

\section{Funding}

This research was supported under the Australian Research Council's Linkage Projects funding scheme (project LP0776879).

Conflict of interest

All authors declare that they have no conflicts of interest. 
References

Abdallah, A. B., Scheier, L. M., Inciardi, J. A., Copeland, J., \& Cottler, L. B. (2007). A psycho-economic model of ecstasy consumption and related consequences: A multisite study with community samples. Substance Use \& Misuse, 42(11), 1651-1684.

Akbar, T., Baldacchino, A., Cecil, J., Riglietta, M., Sommer, B., \& Humphris, G. (2011). Poly-substance use and related harms: A systematic review of harm reduction strategies implemented in recreational settings. Neuroscience \& Biobehavioural Reviews, 35(5), 1186-1202.

Baggott, M. J. (2002). Preventing problems in Ecstasy users: Reduce use to reduce harm. Journal of Psychoactive Drugs, 34(2), 145-162.

Baylen, C. A., \& Rosenberg, H. (2006). A review of the acute subjective effects of MDMA/ecstasy. Addiction, 101(7), 933-947.

Boeri, M., Sterk, C., \& Elifson, K. (2004). Rolling beyond raves: Ecstasy use outside the rave setting. Journal of Drug Issues, 34(4), 831-860.

Boys, A., \& Marsden, J. (2003). Perceived functions predict intensity of use and problems in young polysubstance users. Addiction, 98(7), 951-963.

Bruno, R., Matthews, A., Topp, L., Degenhardt, L., Gomez, R., \& Dunn, M. (2009). Can the severity of dependence scale be usefully applied to 'ecstasy'? Neuropsychobiology, 60(3-4), 137-147.

Degenhardt, L., Bruno, R., \& Topp, L. (2010). Is ecstasy a drug of dependence? Drug and Alcohol Dependence, 107(1), 1-10.

Degenhardt, L., Roxburgh, A., Dunn, M., Campbell, G., Bruno, R., Kinner, S., ... Topp, L. (2009). The epidemiology of ecstasy use and harms in Australia.

Neuropsychobiology, 60(3-4), 176-187.

Duff, C. (2005). Party drugs and party people: Examining the 'normalization' of recreational 
drug use in Melbourne, Australia. International Journal of Drug Policy, 16(3), 161170.

Engels, R. C., \& ter Bogt, T. (2004). Outcome expectancies and ecstasy use in visitors of rave parties in the Netherlands. European Addiction Research, 10(4), 156-162.

Falck, R. S., Carlson, R. G., Wang, J., \& Siegal, H. A. (2004). Sources of information about MDMA (3,4-methylenedioxymethamphetamine): Perceived accuracy, importance, and implications for prevention among young adult users. Drug and Alcohol Dependence, 74(1), 45-54.

Goudie, A. J., Sumnall, H. R., Field, M., Clayton, H., \& Cole, J. C. (2007). The effect of price and perceived quality on the behavioural economics of alcohol, amphetamine, cannabis, cocaine, and ecstasy purchases. Drug and Alcohol Dependence, 89(2-3), 107-115.

Green, A. R., Mechan, A. O., Elliott, J. M., O’Shea, E., \& Colado, M. I. (2003). The pharmacology and clinical pharmacology of 3,4-methylenedioxymethamphetamine (MDMA, “ecstasy”). Pharmacological Review, 55(3), 463-508.

Haro, J. M., Arbabzadeh-Bouchez, S., Brugha, T. S., de Girolamo, G., Guyer, M. E., Jin, R., ... Kessler, R. C. (2006). Concordance of the Composite International Diagnostic Interview Version 3.0 (CIDI 3.0) with standardized clinical assessments in the WHO World Mental Health surveys. International Journal of Methods in Psychiatric Research, 15(4), 167-180.

Hunt, G. P., \& Evans, K. (2008). 'The great unmentionable': Exploring the pleasures and benefits of ecstasy from the perspectives of drug users. Drugs: Education, Prevention and Policy, 15(4), 329-349.

Hunt, G., Moloney, M., \& Fazio, A. (2014). “A cool little buzz”: Alcohol intoxication in the dance club scene. Substance Use \& Misuse, 49(8), 968-981. 
Jacinto, C., Duterte, M., Sales, P., \& Murphy, S. (2008). "I'm not a real dealer”: The identity process of ecstasy sellers. Journal of Drug Issues, 38(2), 419-444.

Kavanaugh, P. R., \& Anderson, T. L. (2008). Solidarity and drug use in the electronic dance music scene. The Sociological Quarterly, 49(1), 181-208.

Kelly, B. C., LeClair, A., \& Parsons, J. T. (2013). Methamphetamine use in club subcultures. Substance Use \& Misuse, 48(14), 1541-1552.

Kypri, K., Paschall, M. J., Maclennan, B., \& Langley, J. D. (2007). Intoxication by drinking location: A web-based diary study in a New Zealand university community. Addictive Behaviors, 32(11), 2586-2596.

LaBrie, J. W., Grant, S., \& Hummer, J. F. (2011). "This would be better drunk": Alcohol expectancies become more positive while drinking in the college social environment. Addictive Behaviors, 36(8), 890-893.

Lee, J. P., Battle, R. S., Soller, B., \& Brandes, N. (2011). Thizzin' - Ecstasy use contexts and emergent social meanings. Addiction Research \& Theory, 19(6), 528-541.

Lende, D. H., Leonard, T., Sterk, C. E., \& Elifson, K. (2007). Functional methamphetamine use: The insider's perspective. Addiction Research \& Theory, 15(5), 465-477.

Miller, B. A., Furr-Holden, C. D., Voas, R. B., \& Bright, K. (2005). Emerging adults’ substance use and risk behaviours in club settings. Journal of Drug Issues, 35(2), 357378.

Miller, B. A., Holder, H. D., \& Voas, R. B. (2009). Environmental strategies for prevention of drug use and risk in clubs. Journal of Substance Use, 14(1), 19-38.

Sanders, B. (2005). In the club: Ecstasy use and supply in a London nightclub. Sociology, 39(2), 241-258.

Singer, E. O., \& Schensul, J. J. (2011). Negotiating ecstasy risk, reward, and control: A 
qualitative analysis of drug management patterns among ecstasy-using urban young adults. Substance Use \& Misuse, 46(13), 1675-1689.

Smirnov, A., Kemp, R., Wells, H., Legosz, M., \& Najman, J. M. (2014). Using population screening for recruitment of young adults engaged in illicit drug use: Methodological issues and sampling outcomes. Social Science Research, 45(1), 89-97.

Smirnov, A., Najman, J. M., Hayatbakhsh, R., Plotnikova, M., Wells, H., Legosz, M., \& Kemp, R. (2013). Young adults' trajectories of Ecstasy use: A population based study. Addictive Behaviors, 38(11), 2667-2674.

ter Bogt, T., \& Engels, R. C. (2005). "Partying" hard: Party style, motives for and effects of MDMA use at rave parties. Substance Use \& Misuse, 40(9-10), 1479-1502.

Van Havere, T., Vanderplasschen, W., Lammertyn, J., Broekaert, E., \& Bellis, M. (2011). Drug use and nightlife: More than just dance music. Substance Abuse, Treatment, Prevention and Policy, 6(1), 1-18.

Vervaeke, H., van Deursen, L., \& Korf, D. (2008). The role of peers in the initiation and continuation of ecstasy use. Substance Use \& Misuse, 43(5), 633-646.

von Sydow, K., Lieb, R., Pfister, H., Höfler, M., \& Wittchen, H. (2002). Use, abuse and dependence of ecstasy and related drugs in adolescents and young adults - A transient phenomenon? Results from a longitudinal community study. Drug and Alcohol Dependence, 66(2), 147-159.

Zou, G. (2004). A modified Poisson regression approach to prospective studies with binary data. American Journal of Epidemiology, 159(7), 702-706. 
Table 1. Baseline characteristics - Ecstasy users ( $n=265)$ vs. non-users $(n=200)$

\begin{tabular}{|c|c|c|c|}
\hline & $\begin{array}{c}\text { Ecstasy users } \\
\text { n (\%) }\end{array}$ & $\begin{array}{c}\text { Non-users } \\
\mathrm{n}(\%)\end{array}$ & Test statistic \\
\hline Sex & & & $\chi^{2}=2.38$ \\
\hline Male & $125(47.2)$ & $80(40.0)$ & \\
\hline Female & $140(52.8)$ & $120(60.0)$ & \\
\hline Age & & & $t=0.88$ \\
\hline Median age (range) & 21 years (19-23 years) & 21 years (19-23 years) & \\
\hline Income & & & $\chi^{2}=30.90 * * *$ \\
\hline $0-\$ 550$ per fortnight & $68(26.1)$ & $91(45.5)$ & \\
\hline$\$ 551-\$ 975$ per fortnight & $60(23.0)$ & $54(27.0)$ & \\
\hline$\$ 976-\$ 1,300$ per fortnight & $69(26.4)$ & $21(10.5)$ & \\
\hline$>\$ 1,300$ per fortnight & $64(24.5)$ & $34(17.0)$ & \\
\hline Education & & & $\chi^{2}=5.89$ \\
\hline Less than high school & $26(9.8)$ & $8(4.0)$ & \\
\hline Completed high school & $163(61.5)$ & $127(63.5)$ & \\
\hline More than high school & $76(28.7)$ & $65(32.5)$ & \\
\hline Employment status & & & $\chi^{2}=0.53$ \\
\hline Unemployed & $36(13.6)$ & $32(16.0)$ & \\
\hline Full or part-time employment & $229(86.4)$ & $168(84.0)$ & \\
\hline Attending an educational institution & & & $\chi^{2}=3.58$ \\
\hline No & $128(48.3)$ & $79(39.5)$ & \\
\hline Attending full or part-time & $137(51.7)$ & $121(60.5)$ & \\
\hline
\end{tabular}

Note: $\quad * * * p<0.001$

${ }^{a}$ Number within each category; ${ }^{b}$ Refers to average fortnightly income after tax, including benefits; ${ }^{c}$ Includes universities, technical or further education institutions, and schools 
Table 2. Proportions of ecstasy users who increased, decreased, or reported stable frequency of ecstasy use between the 12- and 30-month follow-up ( $n=265)$

\section{Frequency of ecstasy use at $\mathbf{3 0}$ months}

n (\%)

$92(34.7)$

50 (18.9)
Days of ecstasy use at $\mathbf{3 0}$ months Mean $(95 \% \mathrm{Cl})$

$21.7(15.06-28.27)$

$1.6(0.94-2.35)$

$4.2(3.60-4.72)$ $0(0)$

No use ${ }^{c}$

${ }^{a}$ Increased use refers to an increase to at least monthly ecstasy use at 30 months; Stable high frequency use refers to monthly ecstasy use in the last 12 months at both the 12- and 30-month follow-ups; ${ }^{b}$ Low frequency use refers to less than monthly use; ${ }^{c}$ No ecstasy use in the last 12 months at the 12 -month or 30-month follow-up 
Table 3. Predictors of frequent ecstasy use at 30 months - multivariate Poisson regression reporting unadjusted and adjusted ${ }^{\text {a }}$ relative risk $(n=265)$

\begin{tabular}{|c|c|c|c|}
\hline & $n^{b}$ & $\begin{array}{l}\text { Unadjusted Relative Risk } \\
\text { (95\% Confidence Interval) }\end{array}$ & $\begin{array}{c}\text { Adjusted Relative Risk } \\
\text { (95\% Confidence Interval) }\end{array}$ \\
\hline \multicolumn{4}{|l|}{ Monthly+ venue attendance ${ }^{c}$} \\
\hline Nightclubs & 153 & $5.86(1.80-19.01)^{* *}$ & $6.21(2.30-16.76)^{* * *}$ \\
\hline \multicolumn{4}{|l|}{ Electronic dance music events } \\
\hline (EDMEs)/Music festivals & 43 & $1.48(0.63-3.44)$ & $0.62(0.25-1.52)$ \\
\hline Venues playing live music & 78 & $1.92(0.94-3.91)$ & $2.18(0.95-4.98)$ \\
\hline Pubs/bars & 183 & $1.06(0.49-2.33)$ & $0.47(0.18-1.23)$ \\
\hline \multicolumn{4}{|l|}{ Ecstasy use expectancies } \\
\hline Strong positive subjective effects ${ }^{d}$ & 89 & $2.47(1.21-5.06)^{*}$ & $2.17(1.08-4.36)^{*}$ \\
\hline \multicolumn{4}{|l|}{ Ecstasy availability } \\
\hline Ready access to ecstasy at 30 months $^{e}$ & 85 & $1.97(0.97-4.00)$ & $2.67(1.19-6.00)^{*}$ \\
\hline \multicolumn{4}{|l|}{ Ecstasy-using peers } \\
\hline$\geq 40$ ecstasy-using peers at baseline & 154 & $3.17(1.24-8.13)^{*}$ & $2.43(0.92-6.42)$ \\
\hline \multicolumn{4}{|l|}{ Ecstasy involvement } \\
\hline \multicolumn{4}{|l|}{ Years of ecstasy use ${ }^{f}$ : } \\
\hline $4-5$ years & 69 & $1.11(0.51-2.45)$ & $1.23(0.56-2.69)$ \\
\hline $6-9$ years & 23 & $0.42(0.06-3.00)$ & $0.60(0.09-3.98)$ \\
\hline \multicolumn{4}{|l|}{ Lifetime ecstasy dependence at 12} \\
\hline months ${ }^{\mathrm{g}}$ & 122 & $1.70(0.82-3.54)$ & $1.94(0.93-4.05)$ \\
\hline \multicolumn{4}{|l|}{ Demography } \\
\hline Sex (male) & 125 & $1.21(0.59-2.47)$ & $1.08(0.54-2.16)$ \\
\hline
\end{tabular}

Note: $\quad * \mathrm{p}<0.05, * * \mathrm{p}<0.01, * * * \mathrm{p}<0.001$

${ }^{a}$ Relative risk for each variable adjusted for all other variables in the model; ${ }^{b}$ Number within each category; ${ }^{c}$ Attendance in last 12 months, measured at 6 months; reference category is less than monthly; ${ }^{d}$ Measured at baseline; report 'every time or almost every time I use' experiencing at least 5 of 6 measured positive subjective effects on occasions of ecstasy use; ${ }^{\text {e }}$ Ready access refers to 'never' or 'rarely' being unable to acquire ecstasy when wanted in last 12 months at 30-month follow-up; ${ }^{\mathrm{f}}$ Reference category is $0-3$ years; $^{\mathrm{g}}$ Assessed using the WMH-CIDI 3.0, which applies diagnostic criteria from the DSM-IV 